\title{
Meditation: should a cardiologist care?
}

\author{
Stephen Olex \\ Einstein Institute for Heart and Vascular Health, Einstein Medical Center \\ Andrew B. Newberg, MD \\ The Myrna Brind Center for Integrative Medicine, Jefferson Medical College, \\ Vincent M. Figueredo, M.D. \\ Thomas Jefferson University
}

\section{Follow this and additional works at: https://jdc.jefferson.edu/cardiologyfp \\ Part of the Cardiology Commons \\ Let us know how access to this document benefits you}

\section{Recommended Citation}

Olex, Stephen; Newberg, MD, Andrew B.; and Figueredo, M.D., Vincent M., "Meditation: should a cardiologist care?" (2013). Division of Cardiology Faculty Papers. Paper 29.

https://jdc.jefferson.edu/cardiologyfp/29

This Article is brought to you for free and open access by the Jefferson Digital Commons. The Jefferson Digital Commons is a service of Thomas Jefferson University's Center for Teaching and Learning (CTL). The Commons is a showcase for Jefferson books and journals, peer-reviewed scholarly publications, unique historical collections from the University archives, and teaching tools. The Jefferson Digital Commons allows researchers and interested readers anywhere in the world to learn about and keep up to date with Jefferson scholarship. This article has been accepted for inclusion in Division of Cardiology Faculty Papers by an authorized administrator of the Jefferson Digital Commons. For more information, please contact: JeffersonDigitalCommons@jefferson.edu. 


\section{As submitted to: \\ International Journal of Cardiology}

And later published as:

Meditation: Should a Cardiologist Care?

\section{October 2013, Volume 168, Issue 3, pp. 1805-10.}

\section{DOI: 10.1016/j.jjcard.2013.06.086}

Stephen Olex ${ }^{1}, \mathrm{MD}$, Andrew Newberg $\mathrm{MD}^{2}$, and Vincent M. Figueredo $\mathrm{MD}^{1,3}$

Einstein Institute for Heart and Vascular Health, Einstein Medical Center, Philadelphia, $\mathrm{PA}^{1}$, The Myrna Brind Center for Integrative Medicine, Jefferson Medical College, Philadelphia, $\mathrm{PA}^{2}$, and Jefferson Medical College, Philadelphia, PA $^{3}$

Disclosures: no conflict of interest or funding sources for preparation of this manuscript.

Address correspondence to: Stephen Olex, MD

Einstein Institute for Heart and Vascular Health

5501 Old York Road, 3rd Floor Levy Building

Philadelphia, PA 19141

TEL: 215-456-8991

FAX: 215-456-3533,

E-mail: olexstep@einstein.edu 
Abstract:

Meditation refers to a family of practices that may share many similarities, but can have differences in underlying methods and goals. Religious and spiritual associations are common but are not requisite for meditation practice and it should be recognized that the basis of many if not all practices is the training of the brain and body, a process that appears to have profound effects on both structure and function. In recent decades there has been interest regarding the effects of these ancient practices on the cardiovascular system, as meditation has intuitive appeal for benefit in this area. Though there is a relative shortage of quality data, available evidence suggests that meditation may exert beneficial effects on autonomic tone, autonomic reflexes, and decrease blood pressure acutely and after long term practice. In addition, meditation has the potential to positively influence the cardiovascular system through mind-heart connection and the anti-inflammatory reflex. There is limited but promising data to suggest that meditation based interventions can have beneficial effects on patients with established cardiovascular disease. More high quality and unbiased studies of meditation practices on relevant endpoints in cardiovascular disease are needed, including the effects of such practices on inflammation, baseline heart rate variability, arrhythmias, myocardial infarction, and cardiovascular mortality.

Key words: meditation, cardiovascular disease, autonomic dysfunction, inflammation, mindheart connection 
Meditation refers to a family of practices that may share many similarities, but can have differences in underlying methods and goals. The absence of a succinct yet thorough definition of meditation as well as a lack of exposure likely contribute to misconceptions regarding the practices in both the lay and scientific communities. The initial goal here is not to attempt the daunting task of providing a thorough definition of meditation or to introduce a classification system, but to give a brief overview of the building blocks of common meditation practices and how they might relate to the cardiovascular system and cardiovascular health.

Meditative practices may involve focused attention during which the practitioner directs his or her consciousness on breathing, an object, or a word or phrase known as a mantra. The focus of attention can also involve a greater awareness of all thoughts, emotions, and sensations that the individual has in a practice known as mindfulness meditation. Other practices strive to cultivate particular feelings such as love or compassion for self and others.

Many meditation practices place emphasis on experiencing the present moment. To counteract the natural tendency of the human mind to think about the past or future, skill in concentration is developed to allow the practitioner to focus primarily on immediate conscious phenomena. The inevitable wandering of the mind is acknowledged when it is noted to occur and attention is then directed back to where it is intended to be. This process occurs time and again and serves to strengthen concentration and ultimately the connection with the present moment. In more intense practices, the mental state of "thoughtless awareness" with a deep sense of physical and mental calm and enhanced pure awareness may result. ${ }^{1}$

Though most often associated with Buddhism and Hinduism, meditative practices are also found in many if not all of the major religions of the world. Often, such practices include specific content that is related to the religious tradition. However, meditation practices may have 
spiritual meaning for those that practice in the absence of a formal religious belief system. Many practices today, including mindfulness or yoga based practices, are quite secularized compared to their traditions of origin. Thus, religious and spiritual associations are not requisite for practice and it should be recognized that the basis of many if not all practices is the training of the brain and body, a process that appears to have profound effects on both structure and function.

For thousands of years those that practice meditation have believed in the beneficial effects on the mind and body. Within the last half century, there has been an increase in scientific research that has studied the physiology of meditation practices and their effects in health and disease. There has been recent interest regarding the effects of meditation on the cardiovascular system, as meditation has intuitive appeal for benefit in this area. This review will explore the theoretical rationale and supporting data for the ability of meditation to exert a positive influence on the cardiovascular system and assess the current body of research on meditation in patients with cardiovascular disease. While movement based practices such as yoga or tai chi have meditative components, this review will focus on stationary meditation practices.

\section{The Autonomic Nervous System}

Chronic imbalance of the autonomic nervous system in the form of increased sympathetic tone and/or decreased parasympathetic tone is a powerful risk factor for cardiovascular morbidity and mortality. ${ }^{2,3}$ Sympathetic activation increases cardiovascular workload and contributes to endothelial dysfunction, coronary spasm, left ventricular hypertrophy, myocardial infarction, arrhythmias, and sudden death. ${ }^{3}$ Diverse factors that negatively affect the autonomic nervous system balance including insulin resistance and metabolic syndrome, sympathomimetic medications or recreational drugs, and acute and chronic psychosocial stressors are associated 
with increased risk of cardiovascular events. Conversely, therapies that offer a more favorable autonomic balance such as exercise, beta-blockers, and angiotensin converting enzyme inhibitors can reduce cardiovascular morbidity and mortality. ${ }^{3}$ Described as a wakeful hypometabolic state $^{4}$, meditation practices can acutely exert significant influence on autonomic tone with parasympathetic activation. ${ }^{5}$ The regular practice of meditation may favorably affect baseline autonomic balance $^{6}$, though this requires further study.

Heart Rate Variability and Autonomic Reflexes

Heart rate variability, a measure of the variation of instantaneous heart rate over time, can provide a window into the functioning of the autonomic nervous system and autonomic balance. Low heart rate variability has been associated with increased risk of cardiovascular events and mortality, and has also been associated with a poor prognosis in heart failure and post myocardial infarction. ${ }^{7-11}$ Increased HRV appears cardioprotective in most, but not all groups (for example, those with sinus node dysfunction), as demonstrated in the Rotterdam Study. ${ }^{12}$

Three sub-bands of heart rate variability of particular interest include high frequency oscillations $(0.15-0.4 \mathrm{~Hz})$, low frequency oscillations $(0.04-0.15 \mathrm{~Hz})$, and very low frequency oscillations $(0.0033-0.04 \mathrm{~Hz}) .{ }^{13} \quad$ A thorough discussion of heart rate variability is outside the scope of this review, therefore only the more relevant points will be discussed here. Respiratory sinus arrhythmia (RSA) is the normal physiologic phenomenon during which the heart rate increases with inspiration and decreases with expiration. As vagal activity is a major contributor to RSA, the phenomenon has been utilized as a marker of parasympathetic tone. ${ }^{13}$ At normal breathing rates, these respiratory oscillations fall into the high frequency sub-band and consequently high 
frequency heart rate variability is thought to reflect parasympathetic tone. The origin of inherent low frequency oscillations is controversial but the dominant theory postulates that the baroreflex is responsible for low frequency variation through a feedback loop while another theory holds that low frequency oscillations are generated by a central brain stem

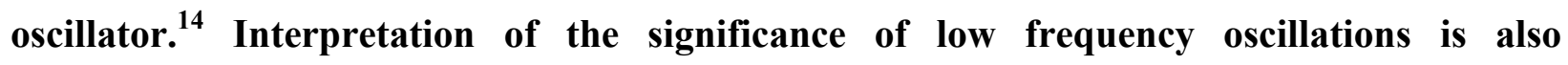
controversial; low frequency variability is thought to reflect either autonomic balance or sympathetic activity. The significance of very low frequency oscillations is uncertain. ${ }^{13}$

During meditation, the respiratory rate commonly decreases and heart rate variability from RSA may decrease to the low frequency range of heart rate variability. At approximately 6 breaths per minute or $0.1 \mathrm{~Hz}$, RSA synchronizes with inherent low frequency variability leading to significantly increased amplitude of heart rate variability. ${ }^{15-19}$ (Figure 1) This is the same physiology that occurs during biofeedback training to increase heart rate variability. ${ }^{20} \mathrm{~A}$ rate of breathing of 6 breaths per minute or $0.1 \mathrm{~Hz}$ also coincides with and augments the intrinsic blood pressure variation known as the Mayer wave ${ }^{21}$, a complex phenomenon of autonomic activity that results in an approximately 10 second cycle $(0.1 \mathrm{~Hz}$ or 6 per minute $)$ of blood pressure. ${ }^{22}$ Of interest, it has been shown that during recitation of the Ave Maria in Latin and during recitation of a yoga mantra subjects spontaneously decreased their respiratory rate to 6 breaths per minute, which augmented heart rate variability and Mayer wave amplitude and even resulted in rhythmic fluctuations in cerebral blood flow. ${ }^{21}$

The significance of this entrainment of cardiovascular oscillations is not completely known, but breathing at 6 per minute has been shown to increase baroreflex sensitivity. ${ }^{23}$ It is well established that baroreceptor abnormalities are associated with a poor prognosis in chronic heart failure and post-myocardial infarction. ${ }^{24,25}$ Lower rates of breathing 
(approximately 6 breaths per minute) have been shown to increase baroreflex sensitivity in heart failure, hypertension, diabetic autonomic neuropathy, and healthy controls. ${ }^{26-28}$ The baroreflex has a tonic influence on the chemoreflex, and it has been demonstrated that an enhanced baroreflex inhibits the chemoreflex while a depressed baroreflex results in an augmented chemoreflex. ${ }^{23}$ Slow deep breathing, through baroreflex augmentation, has been demonstrated to inhibit chemoreflex sensitivity with subsequent decrease of sympathetic tone. $^{23}$ Research is needed to determine if regular meditation or slow breathing can over time increase baseline heart rate variability and baroreflex sensitivity through favorably affecting baseline autonomic tone.

\section{The Anti-Inflammatory Reflex}

Inflammation appears to play a central role in atherosclerotic plaque progression, vulnerability, and thrombogenicity ${ }^{29,30}$, and has been implicated in the pathophysiology of heart failure. $^{2}$ Data suggests that the vagus nerve represents the efferent and afferent limbs of a cholinergic anti-inflammatory reflex that serves to decrease the detrimental effects of excessive proinflammatory stimulation. ${ }^{31}$ Vagal afferents sense peripheral inflammation and transmit action potentials from the periphery to the brain stem. Efferent vagal activity is then enhanced and information relayed to the spleen and other organs where proinflammatory cytokines are inhibited and inflammation is limited. ${ }^{31-33}$ (Figure 2)

In addition to giving us a window into vagal efferent activity to the heart and parasympathetic tone, heart rate variability may also give us insight into the activity of the anti-inflammatory reflex. Heart rate variability has been shown to be inversely related to inflammatory markers such as C-reactive protein and interleukin-6 (IL-6), ${ }^{34,35}$ which is likely reflective of a direct but complex relationship between vagal efferent activity to the 
heart and the efferent arm of the anti-inflammatory reflex. Evidence suggests that the beneficial effects of exercise may be mediated, at least in part, through this anti-inflammatory reflex. $^{36}$ The potential favorable effects of meditation on autonomic tone have the potential to produce similar beneficial effects through this reflex, though to date data is limited.

\section{The Mind-Heart Connection}

The mind-heart connection is a complex and powerful relationship. Brain injury is a well documented cause of dramatic electrocardiographic changes and cardiac lesions can result from disease of the central nervous system. ${ }^{37}$ Acute emotional stress has been associated with myocardial infarction, Takutsubo cardiomyopathy, arrhythmias, and sudden cardiac death, while chronic stress at work or at home has been associated with increased risk of incident cardiovascular disease. ${ }^{38-42}$ Anxiety and depression have been associated with increased risk of cardiovascular disease and are common in those with established cardiovascular disease; their added presence in established cardiovascular disease confers a poorer prognosis. ${ }^{40,41,43-48}$

There is a growing body of research which describes the mechanisms of mind-heart interactions. The autonomic nervous system is one of the principal components of the mindheart connection and is one of the fundamental links between thoughts and emotions and the heart. $^{2}$ The anti-inflammatory reflex provides an example of how autonomic function and inflammation interact and contribute to the mind-body communication network. ${ }^{2}$

Major depressive disorder provides a good example of mind-heart interactions. Depression has been associated with sympathetic activation, decreased heart rate variability, and a proinflammatory response evidenced by increased inflammatory cytokines and C-reactive protein. ${ }^{2,49}$ In addition, depression activates the hypothalamic-pituitary adrenocortical (HPA) axis increasing cortisol production leading to insulin resistance, hypertension, and increased 
cardiovascular risk. These factors create an environment that promotes vasoconstriction, endothelial damage, adhesion molecule expression, and platelet aggregation leading to increased risk of coronary artery disease, myocardial infarction, arrhythmias, heart failure, and sudden death. $^{2,40}$

Conversely, autonomic dysfunction and inflammation in the periphery have effects on the central nervous system. It is known that pro-inflammatory stimulation has been associated with cognitive and mood changes as seen in the clinical example of interferon alpha induced depression. ${ }^{2}$ Autonomic imbalance and inflammation in chronic cardiac disease may contribute to cognitive and mood changes in diseases such as congestive heart failure. ${ }^{2}$ Further, an individual with autonomic dysfunction and inflammation as part of their inherent physiology may be at risk for both disorders of the mind and the cardiovascular system.

Subjectively reported benefits of long term meditation include relaxation and stress relief, increased concentration and attention, increased self-control, positive mood, emotional stability, increased resiliency to stress and negative events, as well as an overall enhanced psychoemotional balance. ${ }^{1}$ Objectively, there is evidence for meditation induced effects in the short and long term on functional and structural brain plasticity as well as beneficial effects on relaxation and stress relief. There is also preliminary evidence for enhanced psycho-emotional balance and focused attention skills in those who practice meditation long term. ${ }^{1}$ In addition, there is promising data on the effects of meditation for disorders of mood and anxiety. ${ }^{1}$ Though very limited, data also suggests that meditation may result in improved psychological, hemodynamic, and immune responses to acute stress. ${ }^{50,51}$

As meditation has probable beneficial effects on the mind and the autonomic nervous system, the practice may have a beneficial effect on the cardiovascular system. Data are limited 
but promising on the effects of psychosocial interventions in cardiovascular disease. ${ }^{40,41,52}$ Though not meditation based, a randomized controlled trial in women with coronary artery disease found that a group stress reduction program including relaxation training may prolong life independent of other prognostic factors. ${ }^{52}$

\section{Blood Pressure}

\section{Acute Effects}

The practice of meditation is associated with slower rates of breathing. Slower breathing rates, independent of meditation, have been shown to acutely decrease blood pressure, an effect mediated at least in part through modulation of central and peripheral autonomic tone. ${ }^{23}$ Slow and controlled breathing at 6 breaths per minute has been demonstrated to significantly reduce the blood pressure of hypertensive subjects as well as in chronic heart failure subjects. ${ }^{26,27}$

Transcendental meditation ${ }^{\circledR}(\mathrm{TM} 囚)$ is a widely used and researched meditation program where a word or phrase is mentally repeated as an object of focus. TM® has been shown to decrease systolic blood pressure by $2.5 \mathrm{mmHg}$ acutely in long term practitioners during practice. $^{53}$ However, no acute effect on blood pressure was seen in a study of a similar meditation practice in healthy subjects during a long meditation. ${ }^{54}$ It was hypothesized that this negative result may have been due to achievement of optimal blood pressure at baseline, as the baseline blood pressures were less than national averages.

Factors that likely affect the acute blood pressure response to meditation include baseline sympathetic and parasympathetic tone, systemic vascular resistance, cardiac output, as well as skill in achieving a meditative state. It is possible that those with baseline elevated systemic vascular resistance and/or autonomic imbalance may have a more dramatic acute effect. Ambulatory blood pressure recording of a hypertensive woman who practiced TM® showed a 
marked decrease in pressure during her meditation practice. ${ }^{55}$ (Figure 3)

\section{Chronic Effects}

Early studies demonstrated chronic reductions in blood pressure with meditation practice that disappeared relatively quickly after discontinuation of the practice. ${ }^{56,57}$ The effect of regular practice of $\mathrm{TM}{ }^{\circledR}$ on baseline blood pressure has received considerable attention in recent decades. Trials of TM® in those with normal blood pressure and those with hypertension have demonstrated significant reductions of systolic and diastolic pressures. ${ }^{56,58-61}$ However, many studies on $\mathrm{TM} \circledast$ have been criticized for their quality and possible researcher bias. ${ }^{62,63}$

Three studies considered higher quality utilizing TM® demonstrated: 1 . a $3.4 \mathrm{mmHg}$ reduction in systolic pressure with no significant change in diastolic pressure in patients with coronary artery disease; 2 . a $10.7 \mathrm{mmHg}$ systolic reduction and $6.4 \mathrm{mmHg}$ diastolic reduction in African American adults with hypertension; and 3. a non-significant $3.1 \mathrm{mmHg}$ systolic reduction with a significant $5.7 \mathrm{mmHg}$ diastolic reduction again in African Americans with hypertension. $^{64-67}$ In a 2009 study of $\mathrm{TM}{ }^{\circledR}$ in college students, meditation did not have a significant effect on the blood pressure in the overall group. However, in the group at high risk for hypertension, meditation significantly decreased systolic pressure by $5.0 \mathrm{mmHg}$ and diastolic pressure by $2.8 \mathrm{mmHg}$, compared to increases of $1.3 \mathrm{mmHg}$ systolic and $1.2 \mathrm{mmHg}$ diastolic in controls. $^{68}$

In a study of a contemplation meditation and breathing techniques in the treatment of pharmacologically untreated hypertension, office systolic pressure decreased by $15 \mathrm{mmHg}$ in the treatment group with no change noted in the control group. ${ }^{69}$ The study utilized a very intensive intervention which included 40 minutes of meditation two times per day for 8 weeks. A limitation of this and many controlled studies on meditation is the potential effect of placebo, as 
no validated "sham meditation technique" exists.

\section{Adrenal Hormones}

Intuitively, as meditation produces physiologic results opposite from stress, lower levels of plasma catecholamines would be expected in those that meditate. However, decreased levels of catecholamines in meditators has not been a consistent finding. ${ }^{56}$ There is data to suggest that the relaxation response may reduce the responsiveness of end organs to catecholamines. ${ }^{56}$ Decreased cortisol levels in those that meditate have been a more consistent finding. ${ }^{6,56}$

A small study investigated the effects of meditation on norepinephrine levels in 19 elderly patients with chronic heart failure with both reduced and preserved ejection fraction. ${ }^{70}$ The meditation group was provided instruction in meditation and a 30 minute audiotape with meditation instructions to listen to twice per day for 12 weeks plus a weekly meeting, while the control group had only weekly meetings. After the intervention, the meditation group significantly decreased their norepinephrine levels, a result not noted in the control group. Though promising, the study has limitations including a small sample size and higher baseline norepinephrine levels in the meditation group.

\section{Slow Breathing, Ventilation, and Exercise Capacity in Heart Failure}

Respiratory dysfunction has been documented in congestive heart failure and can contribute to decreased exercise tolerance..$^{71-73}$ In a study of 50 heart failure patients and 11 controls, Bernardi and colleagues found that slow breathing at 6 breaths per minute increased oxygen saturation in heart failure patients, with evidence to suggest this rate was more effective in terms of gas exchange. ${ }^{71}$ In a follow-up study, 15 of the heart failure patients were assigned to one month of respiratory training or rest. The goal of the training was to reduce the breathing rate and to mobilize in sequence the diaphragm, the lower chest, and the upper chest during 
inspiration with the reverse during expiration. Patients underwent symptom-limited upright bicycle cardiopulmonary exercise testing before and after the training. After one month of respiratory training, respiratory rate decreased from $13.4(1.5)$ to $7.6(1.9)(p<0.001)$, peak oxygen consumption increased from $1157(83)$ to $1368(110) \mathrm{L} / \mathrm{min}(\mathrm{p}<0.05)$, and exercise time increased from $583(29)$ to $615(23) \mathrm{min} / \mathrm{s}(\mathrm{p}<0.05)$; changes that were not seen in the control group. ${ }^{71}$ Although the study is limited by small size, it does suggest the potential for respiratory training to improve exercise tolerance in heart failure.

\section{Clinical Trials in Established Cardiovascular Disease}

Data on the effects of meditation on clinical endpoints in established cardiovascular disease are limited. A small study (23 total patients) examined the effects of TM® in African Americans ( $\geq 55$ years) with NYHA class II or III congestive heart failure and ejection fraction

less than $40 \%{ }^{74}$ Subjects were randomized to instruction in $\mathrm{TM} \circledast$ and two at home sessions of meditation for 15-20 minutes per day or health education classes with instructions to read or listen to music for 15-20 minutes two times per day. The meditation group had significant improvements in the primary endpoint of six-minute walk test scores, improving their six-minute walk test score by 50.5 meters from baseline to 6 months compared to the health education group who had a decreased six-minute walk test score by 6.2 meters at 6 months $(\mathrm{p}=0.03)$. There were also improvements in quality of life and depression in the meditation group. Limitations of the study include the very small sample size and short follow up.

The Support Education and Research in Chronic Heart Failure Study (SEARCH) trial demonstrated promise for the role of meditation and mindfulness therapy in the treatment of heart failure. ${ }^{75}$ SEARCH was a prospective cohort study of 208 adults with left ventricular systolic dysfunction (ejection fraction less than or equal to 40\%) and symptoms of congestive 
heart failure. Patients were geographically assigned to either usual care or 2.25 hour weekly meetings in an 8 week course that included mindfulness and meditation training using mindfulness based stress reduction (MBSR) concepts, training in coping skills, and support group discussion. Audiotapes with instructions for guided meditations were provided and patients in the treatment group agreed to practice these skills daily for 30 minutes. Outcome measures were designed to evaluate effects on depression, psychosocial distress, and heart failure symptoms. The mean age was $61,70 \%$ of the patients were male, $46 \%$ had an ischemic etiology for their cardiomyopathy, and mean ejection fraction was $26 \%$. The treatment group had significantly improved symptoms of heart failure at one year compared to the control group. Those in the treatment group also had significantly lower levels of anxiety and depression; an effect that was attenuated at one year. A limitation of the study was that the treatment group assignments were made by geography and not randomization. More recently, TM® was found to decrease a composite of all-cause mortality, myocardial infarction, or stroke in African American patients with coronary heart disease. ${ }^{76}$ Though the results appear promising, analysis of the study and the statistics utilized raise questions making the data at best less

\section{than robust.}

\section{Conclusion}

Theoretical rationale and supporting data exist illustrating the potential of meditation practices to exert significant benefits on the cardiovascular system. As our goals are to help patients live better and longer, there appears to be sufficient evidence regarding meditation practices to recommend them based on the former. More high quality and unbiased studies of meditation practices on relevant endpoints in cardiovascular disease are needed including the effects of such practices on inflammation, baseline heart rate variability, arrhythmias, myocardial 
infarction, and cardiovascular mortality. These studies may establish meditation as a beneficial adjunctive therapy specifically in the prevention and treatment of cardiovascular disease. 


\section{REFERENCES:}

1. Rubia K. The neurobiology of meditation and its clinical effectiveness in psychiatric disorders Biol Psychol. 2009 Sep;82(1):1-11. Epub 2009 Apr 23

2. Emani S, Binkley PF. Mind-body medicine in chronic heart failure: a translational science challenge. Circ Heart Fail. 2010 Nov 1;3(6):715-25

3. Curtis BM, O'Keefe JH Jr. Autonomic tone as a cardiovascular risk factor: the dangers of chronic fight or flight. Mayo Clin Proc. 2002 Jan;77(1):45-54

4. Jevning R, Wallace RK, Beidebach M. The physiology of meditation: a review. A wakeful hypometabolic integrated response. Neurosci Biobehav Rev. 1992 Fall;16(3):415-24.

5. Young JD and Taylor E. Meditation as a Voluntary Hypometabolic State of Biological Estivation. News Physiol Sci. 1998 Jun;13:149-153

6. Sudsuang R, Chentanez V, and Veluvan K. Effect of Buddhist meditation on serum cortisol and total protein levels, blood pressure, pulse rate, lung volume and reaction time. Physiol Behav. 1991 Sep;50(3):543-8

7. Tsuji H, Larson MG, Venditti FJ Jr, Manders ES, Evans JC, Feldman CL, Levy D. Impact of reduced heart rate variability on risk for cardiac events. The Framingham Heart Study Circulation. 1996 Dec 1;94(11):2850-5

8. Dekker JM, Crow RS, Folsom AR, Hannan PJ, Liao D, Swenne CA, Schouten EG.

Low heart rate variability in a 2-minute rhythm strip predicts risk of coronary heart disease and mortality from several causes: the ARIC Study. Atherosclerosis Risk In Communities Circulation. 2000 Sep 12;102(11):1239-44

9. Nolan J, Batin PD, Andrews R, Lindsay SJ, Brooksby P, Mullen M, Baig W, Flapan AD, Cowley A, Prescott RJ, Neilson JM, Fox KA. Prospective study of heart rate variability and mortality in chronic heart failure: results of the United Kingdom heart failure evaluation and assessment of risk trial (UK-heart). Circulation. 1998 Oct 13;98(15):1510-6

10. Huikuri HV, Jokinen V, Syvänne M, Nieminen MS, Airaksinen KE, Ikäheimo MJ, Koistinen JM, Kauma H, Kesäniemi AY, Majahalme S, Niemelä KO, Frick MH. Heart rate variability and progression of coronary atherosclerosis. Arterioscler Thromb Vasc Biol. 1999 Aug;19(8):1979-85

11. Farrell TG, Odemuyiwa O, Bashir Y, Cripps TR, Malik M, Ward DE, Camm AJ. Prognostic value of baroreflex sensitivity testing after acute myocardial infarction. Br Heart J 67: 129-137, 1992

12. de Bruyne MC, Kors JA, Hoes AW, Klootwijk P, Dekker JM, Hofman A, van Bemmel JH, Grobbee DE. Both decreased and increased heart rate variability on the standard 10-second electrocardiogram predict cardiac mortality in the elderly: the Rotterdam Study. Am J Epidemiol. 1999 Dec 15;150(12):1282-8.

13. Xhyheri B, Manfrini O, Mazzolini M, Pizzi C, Bugiardini R. Heart rate variability today. Prog Cardiovasc Dis. 2012 Nov-Dec;55(3):321-31. doi: 10.1016/j.pcad.2012.09.001.

14. Papaioannou VE. Heart Rate Variability, Baroreflex Function and Heart Rate Turbulence: Possible Origin and Implications. Hellenic J Cardiol 48: 278-289, 2007 15. Peng CK, Henry IC, Mietus JE, Hausdorff JM, Khalsa G, Benson H, Goldberger AL. Heart rate dynamics during three forms of meditation. Int J Cardiol. 2004 May;95(1):19-27 16. Phongsuphap S, Pongsupap Y, Chandanamattha P, Lursinsap C. Changes in heart rate variability during concentration meditation. Int J Cardiol. 2008 Nov 28;130(3):481-4. Epub 2007 Aug 30 
17. Lehrer P, Sasaki Y, Saito Y. Zazen and cardiac variability. Psychosom Med. 1999 NovDec;61(6):812-21

18. Peng CK, Mietus JE, Liu Y, Khalsa G, Douglas PS, Benson H, Goldberger AL. Exaggerated heart rate oscillations during two meditation techniques. Int J Cardiol. $1999 \mathrm{Jul}$ 31;70(2):101-7

19. Cysarz D, Büssing A. Cardiorespiratory synchronization during Zen meditation. Eur J Appl Physiol. 2005 Sep;95(1):88-95. Epub 2005 Jun 7

20. Lehrer PM, Vaschillo E, Vaschillo B. Resonant frequency biofeedback training to increase cardiac variability: rationale and manual for training. Appl Psychophysiol Biofeedback. 2000 Sep;25(3):177-91

21. Bernardi L, Sleight P, Bandinelli G, Cencetti S, Fattorini L, Wdowczyc-Szulc J, Lagi A. Effect of rosary prayer and yoga mantras on autonomic cardiovascular rhythms: comparative study. BMJ. 2001 Dec 22-29;323(7327):1446-9

22. Mayer S. Studien zur Physiologie des Herzens und der Blutgefaesse 6. Abhandlung: ueber spontane Blutdruckschwenkungen. [Studies on the physiology of the heart and the blood vessels 6. Discourse on fluctuations in blood pressure.] Sitz Ber Akad Wiss Wien,

Mathe-Naturwiss Kl Anat. 1876;74:281-307

23. Sharma M, Frishman WH, Gandhi K. RESPeRATE: nonpharmacological treatment of hypertension. Cardiol Rev. 2011 Mar-Apr;19(2):47-51

24. Mortara A, La Rovere MT, Pinna GD, Prpa A, Maestri R, Febo O, Pozzoli M, Opasich C, Tavazzi L. Arterial baroreflex modulation of heart rate in chronic heart failure: clinical and hemodynamic correlates and prognostic implications. Circulation. 1997 Nov 18;96(10):3450-8

25. LaRovere MT, Bigger JT Jr, Marcus FI, et al. Baroreflex sensitivity and heart-rate variability in prediction of total cardiac mortality after myocardial infarction. Lancet. 1998;351:478-484

26. Bernardi L, Porta C, Spicuzza L, Bellwon J, Spadacini G, Frey AW, Yeung LY, Sanderson JE, Pedretti R, Tramarin R. Slow breathing increases arterial baroreflex sensitivity in patients with chronic heart failure. Circulation. 2002 Jan 15;105(2):143-5

27. Joseph CN, Porta C, Casucci G, Casiraghi N, Maffeis M, Rossi M, Bernardi L. Slow breathing improves arterial baroreflex sensitivity and decreases blood pressure in essential hypertension Hypertension. 2005 Oct;46(4):714-8. Epub 2005 Aug 29

28. Rosengård-Bärlund $\mathrm{M}$, Bernardi L, Holmqvist J et. al. Deep breathing improves blunted baroreflex sensitivity even after 30 years of type 1 diabetes. Diabetologia. 2011 Jul;54(7):186270. Epub 2011 May 3.

29. Libby P. Inflammation in atherosclerosis. Nature. 2002 Dec 19-26;420(6917):868-74

30. Mizuno Y, Jacob RF, Mason RP. Inflammation and the development of atherosclerosis. J Atheroscler Thromb. 2011;18(5):351-8. Epub 2011 Mar 18

31. Tracey KJ. The inflammatory reflex. Nature. 2002 Dec 19-26;420(6917):853-9

32. Huston JM, Tracey KJ. The pulse of inflammation: heart rate variability, the cholinergic anti-inflammatory pathway and implications for therapy. J Intern Med. 2011 Jan;269(1):45-53. doi: $10.1111 /$ j.1365-2796.2010.02321.x

33. Oke SL, Tracey KJ The Inflammatory Reflex and the Role of Complementary and Alternative Medical Therapies Ann N Y Acad Sci. 2009 Aug;1172:172-80.

34. Sloan RP, McCreath H, Tracey KJ, Sidney S, Liu K, Seeman T. RR interval variability is inversely related to inflammatory markers: the CARDIA study. Mol Med. 2007 Mar-Apr;13(34):178-84 
35. Thayer JF, Fischer JE. Heart rate variability, overnight urinary norepinephrine and Creactive protein: evidence for the cholinergic anti-inflammatory pathway in healthy human adults. J Intern Med. 2009 Apr;265(4):439-47. Epub 2008 Nov 15

36. Sloan RP, Shapiro PA, Demeersman RE, McKinley PS, Tracey KJ, Slavov I, Fang Y, Flood PD. Aerobic exercise attenuates inducible TNF production in humans. $J$ Appl Physiol. 2007 Sep;103(3):1007-11. Epub 2007 Jul 12

37. Samuels MA. The brain-heart connection. Circulation. 2007 Jul 3;116(1):77-84

38. Ziegelstein RC. Acute emotional stress and cardiac arrhythmias. JAMA. $2007 \mathrm{Jul}$ $18 ; 298(3): 324-9$

39. Steinberg JS, Arshad A, Kowalski M, Kukar A, Suma V, Vloka M, Ehlert F, Herweg B, Donnelly J, Philip J, Reed G, Rozanski A. Increased incidence of life-threatening ventricular arrhythmias in implantable defibrillator patients after the World Trade Center attack. J Am Coll Cardiol. 2004 Sep 15;44(6):1261-4

40. Albus C. Psychological and social factors in coronary heart disease. Ann Med. 2010 Oct;42(7):487-94

41. Figueredo VM. The time has come for physicians to take notice: the impact of psychosocial stressors on the heart. Am J Med. 2009 Aug;122(8):704-12

42. Sharkey SW, Lesser JR, Zenovich AG, Maron MS, Lindberg J, Longe TF, Maron BJ. Acute and reversible cardiomyopathy provoked by stress in women from the United States Circulation. 2005 Feb 1;111(4):472-9

43. Martens EJ, de Jonge P, Na B, Cohen BE, Lett H, Whooley MA. Scared to death? Generalized anxiety disorder and cardiovascular events in patients with stable coronary heart disease:The Heart and Soul Study. Arch Gen Psychiatry. 2010 Jul;67(7):750-8

44. Roest AM, Martens EJ, de Jonge P, Denollet J. Anxiety and risk of incident coronary heart disease: a meta-analysis. J Am Coll Cardiol. 2010 Jun 29;56(1):38-46

45. Phillips AC. Generalised anxiety disorder doubles risk of cardiovascular events in people with stable coronary heart disease. Evid Based Ment Health. 2011 Feb;14(1):10

46. Janszky I, Ahnve S, Lundberg I, Hemmingsson T. Early-onset depression, anxiety, and risk of subsequent coronary heart disease: 37-year follow-up of 49,321 young Swedish men. $J$ Am Coll Cardiol. 2010 Jun 29;56(1):31-7

47. Abramson J, Berger A, Krumholz HM, Vaccarino V. Depression and risk of heart failure among older persons with isolated systolic hypertension. Arch Intern Med. $2001 \mathrm{Jul}$ 23;161(14):1725-30

48. Ferketich AK, Binkley PF. Psychological distress and cardiovascular disease: results from the 2002 National Health Interview Survey. Eur Heart J. 2005 Sep;26(18):1923-9. Epub 2005 Jun 9

49. Empana JP, Sykes DH, Luc G, Juhan-Vague I, Arveiler D, Ferrieres J, Amouyel P, Bingham A, Montaye M, Ruidavets JB, Haas B, Evans A, Jouven X, Ducimetiere P; PRIME Study Group. Contributions of depressive mood and circulating inflammatory markers to coronary heart disease in healthy European men: the Prospective Epidemiological Study of Myocardial Infarction (PRIME). Circulation. 2005 May 10;111(18):2299-305. Epub 2005 May 2 50. Barnes VA, Treiber FA, Davis H. Impact of Transcendental Meditation on cardiovascular function at rest and during acute stress in adolescents with high normal blood pressure. J Psychosom Res. 2001 Oct;51(4):597-605 
51. Pace TW, Negi LT, Adame DD, Cole SP, Sivilli TI, Brown TD, Issa MJ, Raison CL. Effect of compassion meditation on neuroendocrine, innate immune and behavioral responses to psychosocial stress. Psychoneuroendocrinology. 2009 Jan;34(1):87-98. Epub 2008 Oct 4 52. Orth-Gomér K, Schneiderman N, Wang HX, Walldin C, Blom M, Jernberg T. Stress reduction prolongs life in women with coronary disease: the Stockholm Women's Intervention Trial for Coronary Heart Disease (SWITCHD). Circ Cardiovasc Qual Outcomes. 2009 Jan;2(1):25-32. Epub 2009 Jan 6

53. Barnes VA, Treiber FA, Turner JR, Davis H, Strong WB. Acute effects of transcendental meditation on hemodynamic functioning in middle-aged adults. Psychosom Med. $1999 \mathrm{Jul}-$ Aug;61(4):525-31

54. Solberg EE, Ekeberg O, Holen A, Ingjer F, Sandvik L, Standal PA, Vikman A. Hemodynamic changes during long meditation. Appl Psychophysiol Biofeedback. 2004 Sep;29(3):213-21

55. Dear JW, Gough K, Webb, DJ. Images in medicine. Transcendental Meditation and Hypertension. Postgrad Med J 2008;84:417 doi:10.1136/pgmj.2008.069757

56. Murphy M and Donovan S, 1999, The Physical and Psychocological Effects of Meditation. A Review of Contemporary Research with a Comprehensive Bibliography 19311996, Institute of Noetic Sciences, Sausalito, California

57. Ospina MB, Bond K, Karkhaneh M, Tjosvold L, Vandermeer B, Liang Y, Bialy L, Hooton N, Buscemi N, Dryden DM, Klassen TP. Meditation practices for health: state of the research. Evid Rep Technol Assess (Full Rep). 2007 Jun;(155):1-263

58. Bagga OP, Gandhi A. A comparative study of the effect of Transcendental Meditation (T.M.) and Shavasana practice on cardiovascular system. Indian Heart J. 1983 Jan-Feb;35(1):3945

59. Alexander CN, Langer EJ, Newman RI, Chandler HM, Davies JL. Transcendental meditation, mindfulness, and longevity: an experimental study with the elderly. J Pers Soc Psychol. 1989 Dec;57(6):950-64

60. Wenneberg SR, Schneider RH, Walton KG, Maclean CR, Levitsky DK, Salerno JW, Wallace RK, Mandarino JV, Rainforth MV, Waziri R. A controlled study of the effects of the Transcendental Meditation program on cardiovascular reactivity and ambulatory blood pressure. Int J Neurosci. 1997 Jan;89(1-2):15-28

61. Castillo-Richmond A, Schneider RH, Alexander CN, Cook R, Myers H, Nidich S, Haney C, Rainforth M, Salerno J. Effects of stress reduction on carotid atherosclerosis in hypertensive African Americans. Stroke. 2000 Mar;31(3):568-73

62. Parati G, Steptoe A. Stress reduction and blood pressure control in hypertension: a role for transcendental meditation? J Hypertens. 2004 Nov;22(11):2057-60

63. Canter PH, Ernst E. Insufficient evidence to conclude whether or not Transcendental Meditation decreases blood pressure: results of a systematic review of randomized clinical trials. J Hypertens. 2004 Nov;22(11):2049-54

64. Anderson JW, Liu C, Kryscio RJ. Blood Pressure Response to Transcendental Meditation: A Meta-analysis. Am J Hypertens. 2008 Mar;21(3):310-6. Epub 2008 Jan 31

65. Paul-Labrador M, Polk D, Dwyer JH, Velasquez I, Nidich S, Rainforth M, Schneider R, Merz CN. Effects of a randomized controlled trial of transcendental meditation on components of the metabolic syndrome in subjects with coronary heart disease. Arch Intern Med. 2006 Jun 12;166(11):1218-24 
66. Schneider RH, Staggers F, Alxander CN, Sheppard W, Rainforth M, Kondwani K, Smith $\mathrm{S}$, King CG. A randomised controlled trial of stress reduction for hypertension in older African Americans. Hypertension. 1995 Nov;26(5):820-7

67. Schneider RH, Alexander CN, Staggers F, Orme-Johnson DW, Rainforth M, Salerno JW, Sheppard W, Castillo-Richmond A, Barnes VA, Nidich SI. A randomized controlled trial of stress reduction in African Americans treated for hypertension for over one year. Am J Hypertens. 2005 Jan;18(1):88-98

68. Nidich SI, Rainforth MV, Haaga DA, Hagelin J, Salerno JW, Travis F, Tanner M, Gaylord-King C, Grosswald S, Schneider RH. A Randomized Controlled Trial on Effects of the Transcendental Meditation Program on Blood Pressure, Psychological Distress, and Coping in Young Adults. Am J Hypertens. 2009 Dec;22(12):1326-31. Epub 2009 Oct 1

69. Manikonda JP, Störk S, Tögel S, Lobmüller A, Grünberg I, Bedel S, Schardt F, Angermann CE, Jahns R, Voelker W. Contemplative meditation reduces ambulatory blood pressure and stress-induced hypertension: a randomized pilot trial. J Hum Hypertens. 2008 Feb;22(2):138-40. Epub 2007 Sep 6

70. Curiati JA, Bocchi E, Freire JO, Arantes AC, Braga M, Garcia Y, Guimarães G, Fo WJ. Meditation reduces sympathetic activation and improves the quality of life in elderly patients with optimally treated heart failure: a prospective randomized study. J Altern Complement Med. 2005 Jun;11(3):465-72

71. Bernardi L, Spadacini G, Bellwon J, Hajric R, Roskamm H, Frey AW. Effect of breathing rate on oxygen saturation and exercise performance in chronic heart failure. Lancet 1998 May 2;351(9112):1308-11

72. Sullivan MJ, Higginbotham MB, Cobb FR. Increased exercise ventilation in patients with chronic heart failure: intact ventilatory control despite hemodynamic and pulmonary abnormalities. Circulation 1988; 77: 552-59

73. Clark A, Coats AJS. The mechanisms underlying the increased ventilatory response to exercise in chronic stable heart failure. Eur Heart $J$ 1992; 13: 1698-708

74. Jayadevappa R, Johnson JC, Bloom BS, Nidich S, Desai S, Chhatre S, Raziano DB, Schneider R. Effectiveness of transcendental meditation on functional capacity and quality of life of African Americans with congestive heart failure: a randomized control study. Ethn Dis. 2007 Winter;17(1):72-7. Erratum in: Ethn Dis. 2007 Summer;17(3):595

75. Sullivan MJ, Wood L, Terry J, Brantley J, Charles A, McGee V, Johnson D, Krucoff MW, Rosenberg B, Bosworth HB, Adams K, Cuffe MS. The Support, Education, and Research in Chronic Heart Failure Study (SEARCH): a mindfulness-based psychoeducational intervention improves depression and clinical symptoms in patients with chronic heart failure. Am Heart J. 2009 Jan;157(1):84-90

76. Schneider RH, Grim CE, Rainforth MV, Kotchen T, Nidich SI, Gaylord-King C, Salerno JW, Kotchen JM, Alexander CN. Stress reduction in the secondary prevention of cardiovascular disease: randomized, controlled trial of transcendental meditation and health education in blacks. Circ Cardiovasc Qual Outcomes. 2012 Nov 1;5(6):750-8. doi: 10.1161/CIRCOUTCOMES.112.967406. Epub 2012 Nov 13. 


\section{FIGURE LEGENDS}

Figure 1. Amplitude of heart rate variability sub-bands (high frequency, low frequency, and very low frequency) during quiet sitting and deep meditation. During quiet sitting heart rate variability is dispersed across the different frequencies. During meditation in this subject, the appearance of a resonant peak with high amplitude occurs at a frequency of $0.1 \mathrm{~Hz}$, likely related to breathing at the same rate. Modified with permission from Phongsuphap S, Pongsupap Y, Chandanamattha $\mathrm{P}$, Lursinsap $\mathrm{C}$ Changes in heart rate variability during concentration meditation Int J Cardiol. 2008 Nov 28;130(3):481-4.

Figure 2. Efferent Limb of the Anti-Inflammatory Reflex. Efferent vagal activity leads to acetylcholine (ACh) release in organs of the reticuloendothelial system resulting in inhibition of pro-inflammatory cytokine release by tissue macrophages. Modified with permission from Tracey KJ. The inflammatory reflex. Nature. 2002 Dec 19-26;420(6917):853-9

Figure 3. Ambulatory blood pressure monitoring of a hypertensive woman that had a striking daytime blood pressure decrease to values lower than that during sleep. Upon review, the decrease corresponded to the woman's meditation practice. Reprinted with permission from Dear JW, Gough K, Webb, DJ. Images in medicine. Transcendental Meditation and Hypertension. Postgrad Med J 2008;84:417 
Figure 1

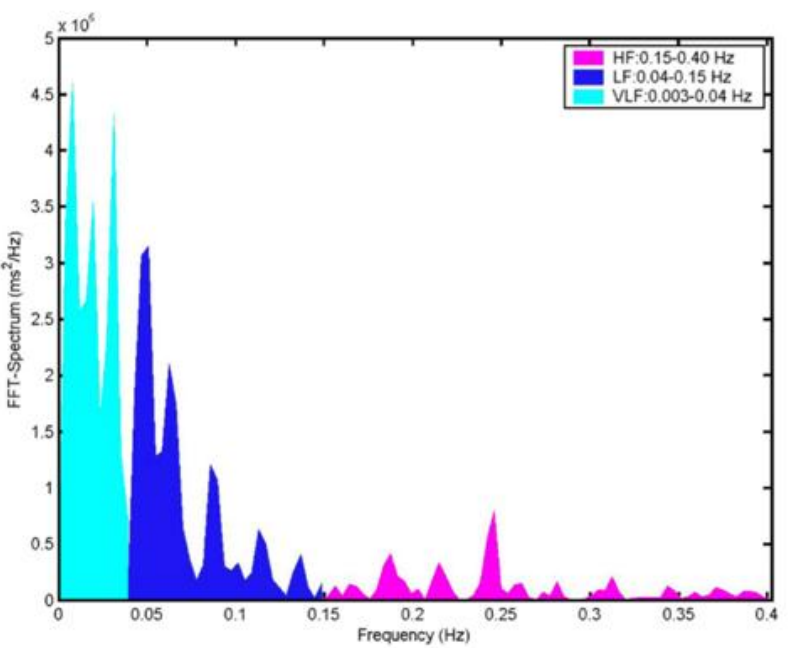

Rest

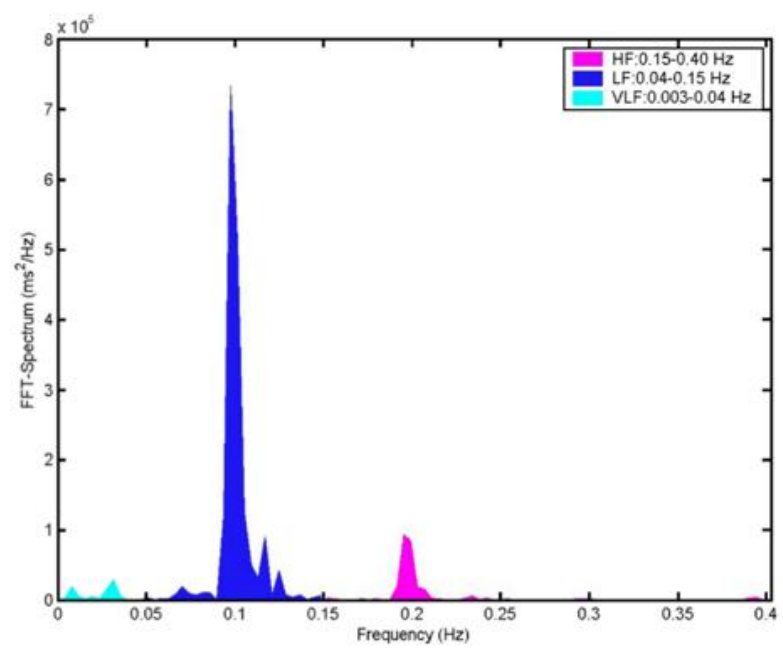

Meditation 
Figure 2

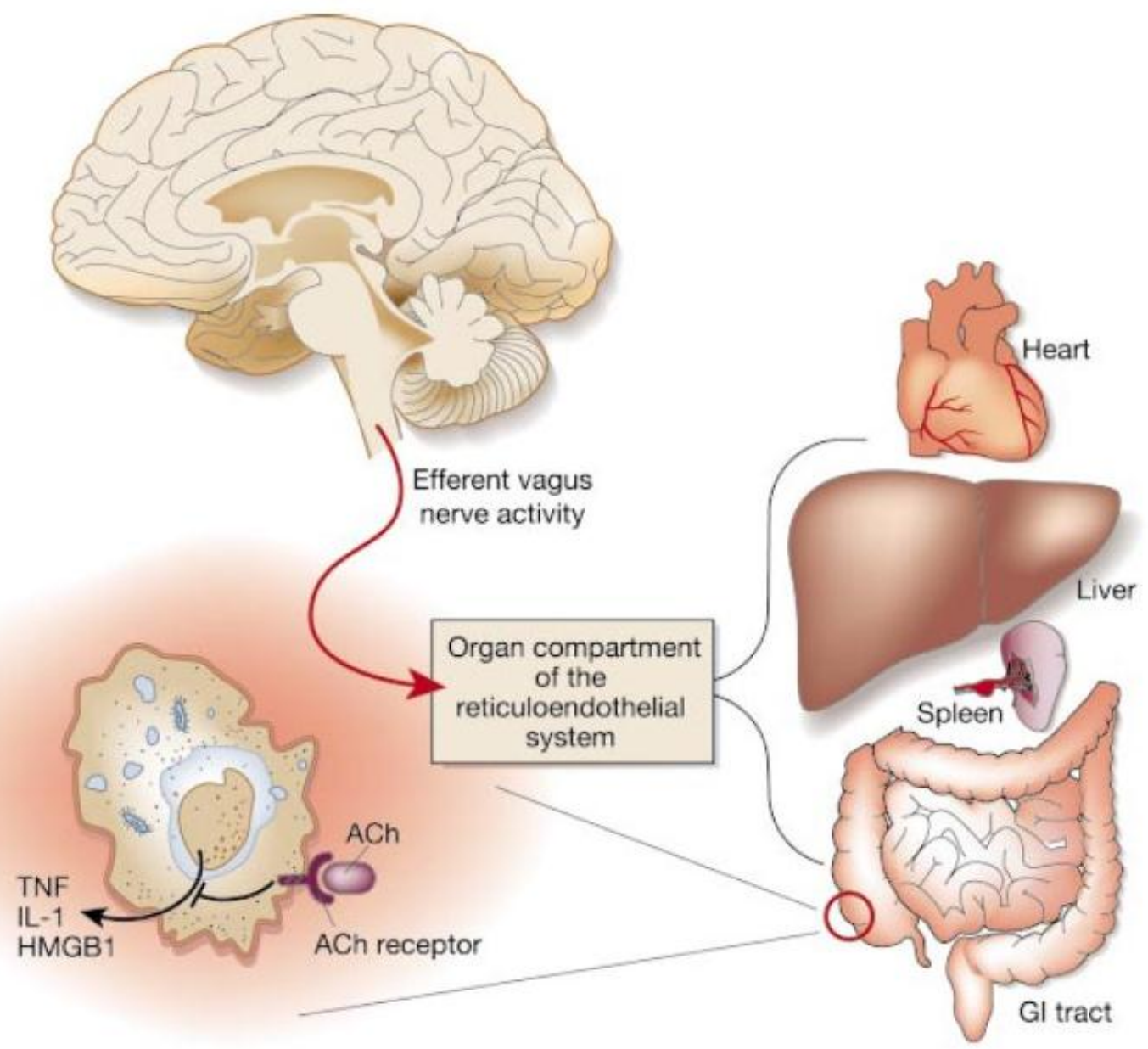


Figure 3

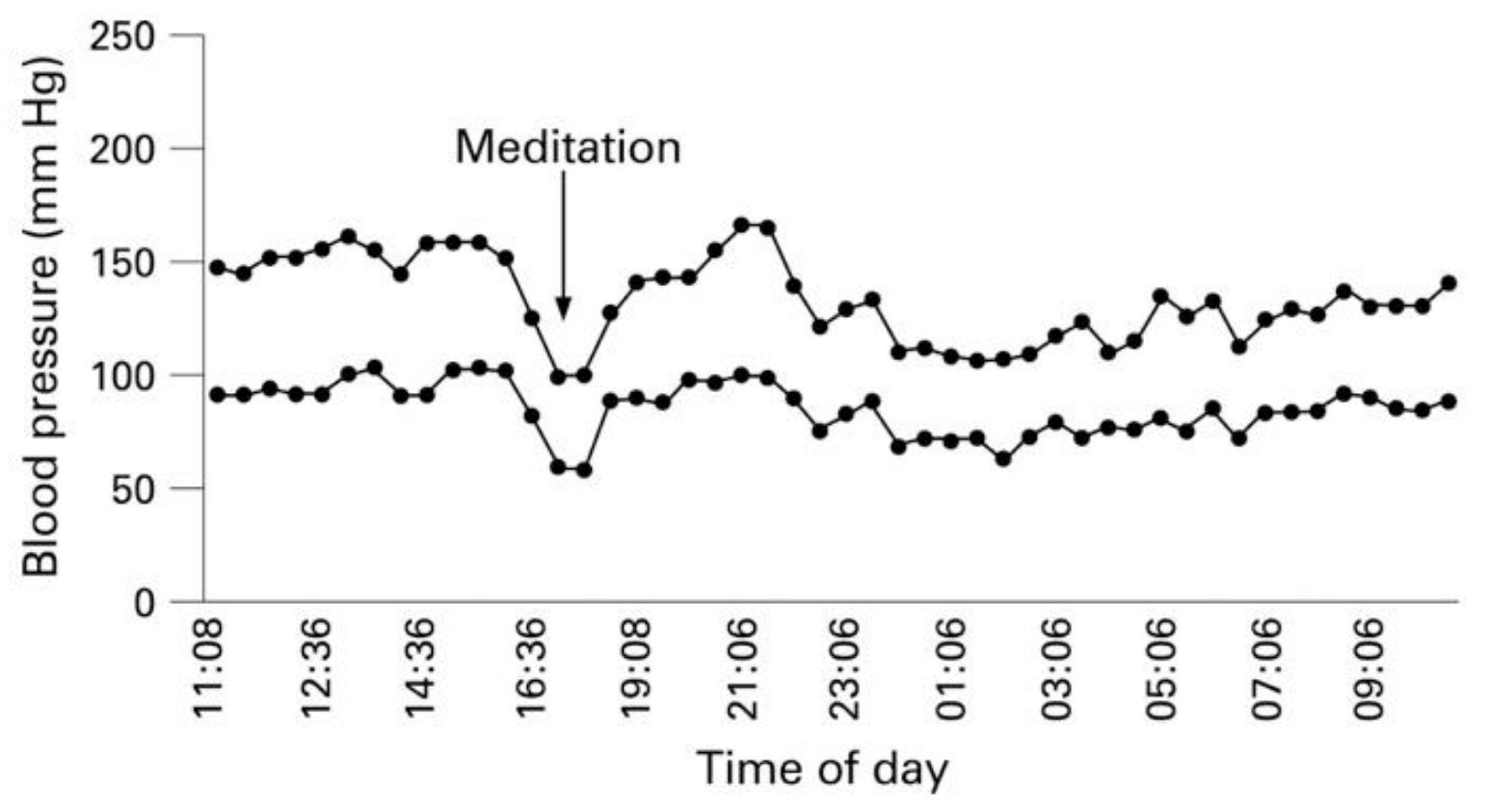

